NASA Technical Memorandum 105369

AIAA-92-0371

\title{
Far-Field Noise and Internal Modes From a Ducted Propeller at Simulated Aircraft Takeoff Conditions
}

Richard P. Woodward

National Aeronautics and Space Administration Lewis Research Center

Cleveland, Ohio

Lawrence A. Bock

Pratt \& Whitney

East Hartford, Connecticut

Laurence J. Heidelberg

National Aeronautics and Space Administration

Lewis Research Center

Cleveland, Ohio

and

David G. Hall

Sverdrup Technology, Inc.

Lewis Research Center Group

Brook Park, Ohio

Prepared for the

30th Aerospace Sciences Meeting and Exhibit

sponsored by the American Institute of Aeronautics and Astronautics

Reno, Nevada, January 6-9, 1992 


\title{
FAR-FIELD NOISE AND INTERNAL MODES FROM A DUCTED PROPELLER AT SIMULATED AIRCRAFT TAKEOFF CONDITIONS
}

\author{
Richard P. Woodward \\ National Aeronautics and Space Administration \\ Lewis Research Center \\ Cleveland, Ohio 44135 \\ Lawrence A. Bock \\ Pratt \& Whitney \\ East Hartford, Connecticut 06108 \\ Laurence J. Heidelberg \\ National Aeronautics and Space Administration \\ Lewis Research Center \\ Cleveland, Ohio 44135 \\ David G. Hall \\ Sverdrup Technology, Inc. \\ Lewis Research Center Group \\ Brook Park, Ohio 44142
}

\begin{abstract}
The ducted propeller offers structural and acoustic benefits typical of conventional turbofan engines while retaining much of the aero-acoustic benefits of the unducted propeller. A model Advanced Ducted Propeller (ADP) was tested in the NASA Lewis LowSpeed Anechoic Wind Tunnel at a simulated takeoff velocity of Mach 0.2. The ADP model was designed and manufactured by the Pratt \& Whitney Division of United Technologies. The 16-blade rotor ADP was tested with 22- and 40-vane stators to achieve cut-on and cut-off criterion with respect to propagation of the fundamental rotor-stator interaction tone. Additional test parameters included three inlet lengths, three nozzle sizes, two spinner configurations, and two rotor rub strip configurations. The model was tested over a range of rotor blade setting angles and propeller axis angles-of-attack. Acoustic data were taken with a sideline translating microphone probe and with a unique inlet microphone probe which identified inlet rotating acoustic modes. The beneficial acoustic effects of cut-off were clearly demonstrated. A $5 \mathrm{~dB}$ fundamental tone reduction was associated with the long inlet and 40-vane stator, which may relate to inlet duct geometry. The fundamental tone level was essentially unaffected by propeller axis angle-of-attack at rotor speeds of at least 96 percent design.
\end{abstract}

\section{Introduction}

The advanced propeller program ${ }^{1,2}$ had successfully demonstrated significant performance improvements for single and counterrotating propellers relative to that of current turbofan engines at typical cruise conditions of Mach 0.8 and $10688 \mathrm{~m}(35000 \mathrm{ft})$ altitude. However, uncertainties over new propeller technologies and inherent structural and acoustic benefits associated with propeller shrouds have directed current research toward the advanced ducted propeller, which is a marriage of the turbofan and propeller technologies. The advanced ducted propeller will typically feature a low number of rotor blades and a stator designed to satisfy the acoustic cut-off criterion. ${ }^{3}$ Bypass ratios of 15 or greater will be characteristic of these powerplants.

The objective of the present study was to quantify the aero-acoustic effects of flow parameters such as inlet length and stator vane number for a model ducted propeller. This paper will present acoustic results for a model Advanced Ducted Propeller (ADP) designed and built by Pratt \& Whitney Division of United Technologies, which was tested in the NASA Lewis 9- by 15-Foot Anechoic Wind Tunnel (Fig. 1(a)). The rotor diameter was $43.8 \mathrm{~cm}$ (17.25 in.). The model was tested with two different stator vane numbers (for 
cut-on and cut-off conditions), three inlets, two spinners, three nozzles, and with grooved and smooth rotor rub strips. A range of rotor blade setting angles was investigated. Limited diagnostic data are included from a unique rotating inlet microphone probe which allowed for separation of individual acoustic modes. Tests were conducted at Mach 0.2 , which is typical of takeoff conditions. Figure $1(\mathrm{a})$ is a photograph of the model installed in the wind tunnel. Acoustic data were obtained from an axially-translating microphone probe. "Flyover" directivities could be obtained from these acoustic probe surveys. Fixed microphones were also located near the tunnel wall in the same approximate plane as the translating probe; however, data from the fixed microphones are not included in this report.

\section{$\underline{\text { Apparatus }}$}

\section{Anechoic Wind Tunnel}

The NASA Lewis 9- by 15-Foot Anechoic Wind Tunnel is located in the low-speed return leg of the supersonic 8 - by 6 -Foot Wind Tunnel. The maximum airflow velocity in the test section is slightly over Mach 0.20 , which provides a takeoff/approach test environment. The tunnel acoustic treatment provides anechoic conditions down to a frequency of $250 \mathrm{~Hz}$, which is lower than the range of test propeller acoustic tones. ${ }^{4}$

\section{Acoustic Instrumentation}

The acoustic data presented in this paper were acquired with the translating microphone probe, which is shown in Fig. 1(a). This probe was instrumented with two $0.64 \mathrm{~cm}$ (0.25 in.) diameter condenser microphones. Data in this report are for the outer microphone, which was located $167 \mathrm{~cm}$ (66 in.) from the propeller axis of rotation at $0^{\circ}$ angle-of-attack. The probe could survey a sideline of approximately $20^{\circ}$ to $140^{\circ}$ relative to the propeller plane. The translating microphone probe allowed measurement of "flyover directivities." The translating probe was programmed to travel at an approximately constant sideline angular velocity. Acoustic surveys required $180 \mathrm{sec}$ to complete. A computer-controlled FFT analyzer was used to acquire 52 representative sound pressure level (SPL) spectra (0 to $20 \mathrm{KHz}$ frequency range, $32 \mathrm{~Hz}$ bandwidth). A computer analysis program then isolated desired tone orders (BPF, $2 \mathrm{BPF}$, etc.) to generate tone sideline directivities.

A unique rotating microphone probe was used with some configurations of the ADP model to perform a detailed investigation of inlet acoustic modes. Figure 1(b) is a photograph showing this probe installed at the ADP inlet.

\section{Model Ducted Propeller}

Table I presents design parameters for the model duct propeller. The ADP model featured a 16-blade rotor ( $43.81 \mathrm{~cm}$ (17.25 in.) diameter) which was tested at four blade pitch angles. The rotor blade setting angle is referenced to the design cruise angle, $0^{\circ}$. A blade setting angle of " $-11^{\circ}$ " is considered to represent the takeoff condition. These blade setting angles are relative to the design cruise blade setting angle. Tests were conducted with both 40 and 22 vane stators. The blade passage tone for the 40 vane stator was predicted to be cut-off at all test rotor speeds according to the blade and vane number criterion of Ref. 3. The ducted propeller was powered by an air turbine drive. Exhaust air from the turbine was ducted well aft of the model and was of no aero-acoustic significance to the test results. The ADP model could be rotated in the horizontal plane to achieve propeller axis angle-of-attack. This model rotation axis was $157 \mathrm{~cm}$ (62 in.) aft of the propeller plane. Table II is a listing of the ADP test configurations. Figure 2 shows a sketch of the forward part of the model with three test inlets and two spinners. 


\section{Results and Discussion}

\section{Cut-Off Effect}

Modern turbofan engines are often designed to take advantage of cut-off whereby the fundamental blade passage tone from rotor-stator interaction is substantially reduced through appropriate selection of blade/vane numbers. ${ }^{3}$ This theory predicts that the fundamental blade passage tone will be cut-off when the number of stator vanes is slightly greater than twice the number of rotor blades. The 40 -vane stator satisfies this criterion for the ADP model.

Figure 3 shows representative SPL spectra for the cut-on (22-vane stator) and cut-off (40-vane stator) configurations. These spectra are for a sideline angle, $\Theta$, of $83^{\circ}$. The fundamental blade passage tone (BPF) is essentially in the broadband for the cut-off configuration (Fig. 3(a)), or about $20 \mathrm{~dB}$ lower than that for the 22-vane stator cut-on spectrum (Fig. 3(b)). Other features of the spectra, such as higher-order tone levels and broadband, are similar for the two stator configurations.

Figure 4 shows corresponding BPF tone sideline directivities for the two stator configurations. The higher BPF tone levels for the 22-vane stator tend to be aft-dominant. This tendency for the fundamental BPF tone to be higher in the aft quadrant has been frequently observed for turbofans. Reference 5 suggests that acoustic blockage of the rotor-stator interaction noise attempting to propagate against the high-velocity rotor airflow is responsible for lower forward quadrant noise. Reflection of rotor-stator noise from the rotor pressure surface to the aft-quadrant is probably insignificant for the BPF tone. ${ }^{6}$

The BPF tone level for the 40-vane cut-off stator configuration still shows some residual tone level at most sideline angles. The broadband directivity in the region of the BPF is shown for reference on Fig. 4. The broadband level for both stator configurations was essen- tially the same. Close inspection of the ADP model did not reveal any likely sources of inflow disturbances which might generate inflow-rotor interaction noise. Reference 7 suggests that small manufacturing irregularities in the stator can result in some rotorstator interaction tone in an otherwise cut-off fan.

\section{Modal Analysis}

Modal analysis may be a useful diagnostic tool in understanding the tone generation mechanisms in turbomachinery. Reference 3 introduced the concept of rotating interaction modes. These modes are defined in terms of circumferential order, $\mathrm{m}$, and radial order, $\mu$ $(\mathrm{m}, \mu)$, where the $(0,0)$ mode would define a plane wave propagating axially down the inlet (or exit) duct. Possible existing circumferential modes are defined by the relationship:

$$
\mathrm{m}=\mathrm{nB}+\mathrm{kV}
$$

where $\mathrm{B}$ and $\mathrm{V}$ are the blade and vane numbers, respectively, and $\mathrm{n}$ is the tone order, $\mathrm{n} \times \mathrm{BPF}$. $\mathrm{k}$ has the value of any \pm integer, including 0 . However, predicted propagation of a particular mode is dependent on having a "cut-off ratio" of 1 or greater.

Reference 8 develops the application of modal theory to include effects of free-stream and duct Mach numbers. From this reference, the mode cut-off ratio is defined as:

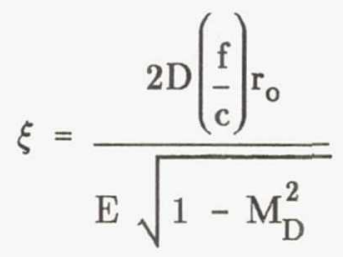

where $\mathrm{f}$ is the tone frequency, $\mathrm{c}$ is the local speed of sound, $r_{0}$ is the "mode release" radius, and $\mathrm{M}_{\mathrm{D}}$ is the duct Mach number. The eigenvalue, E, is a function of the mode order, $(\mathrm{m}, \mu)$. 
Reference 8 gives an expression for the sideline angular location for the maximum level of a particular mode's principal lobe as:

$$
\cos \theta=\frac{M_{\infty}-M_{D}+\left(1-M_{D} M_{\infty}\right) \sqrt{1-\frac{1}{\xi^{2}}}}{\left\{\left[1-M_{D} \sqrt{1-\frac{1}{\xi^{2}}}\right]\left[1+M_{\infty}\left(M_{\infty}-2 M_{D}\right)+\left(2 M_{\infty}-M_{D}-M_{D} M_{\infty}^{2}\right) \sqrt{1-\frac{1}{\xi^{2}}}\right]\right\}^{1 / 2}}
$$

where $\mathbf{M}_{\infty}$ is the free stream Mach. The free stream and duct Mach numbers have a negative sign for modes propagating from the inlet duct, while both are positive for aftpropagating modes.

Tone noise is usually associated with inflow-rotor interaction and rotor-stator interaction. The fundamental BPF tone is cut-off with respect to rotor-stator interaction for the 40-vane stator, but higher tone orders are cut-on with either stator number. There are some practical concerns in applying the modal analysis of Ref. 8. Calculation of the mode cut-off ratio (Eq. (2)) is affected by selection of duct radius $r_{o}$ and duct Mach, $M_{D}$. In the following analysis the inlet highlight radius (see Table I) was chosen as the mode release radius $\left(r_{0}\right)$, while the duct Mach number near the fan face was used for $M_{D}$. It is conceivable that the mode release radius may be somewhat greater than the inlet highlight radius, and that selection of a duct Mach number in another portion of the duct may be more appropriate.

Likewise, Eq. (2) was derived for a cylindrical duct-the existence of an annulus formed by the inlet/nozzle and spinner/ centerbody could also affect the selection of $r_{0}$. Proper selection of these inputs will affect the mode cut-off ratio calculation. The sideline angular location of the acoustic mode principal lobe (Eq. (3)) is similarly affected by the input cut-off ratio and $\mathrm{M}_{\mathrm{D}}$.
The rotating microphone probe was used with the ADP model to perform a detailed investigation of inlet acoustic modes (Fig. 1(b)). Data were taken with the rotating probe and concurrent far field microphones with the 40-vane stator, medium inlet, short spinner and nozzle ADP configuration, although the rotating probe was also tested with the other two ADP inlets without farfield acoustic instrumentation. The model was at $0^{\circ}$ angle-of-attack for these tests. Figure 5 is a sketch of the rotating probe installed with the short ADP inlet. The rotating probe featured a radial rake with five $0.25 \mathrm{~cm}$ (0.10 in.) diameter pressure transducers. The rake rotated at a precise fraction of the rotor speed and was synchronized with the rotor, which allowed for acoustic separation of all " $\mathrm{m}$ " order rotating circumferential modes. The five radial microphones are to provide some indication of the corresponding radial " $\mu$ " mode order. ${ }^{3}$

The ADP model with the rotating probe was run in both a clean inlet and a four-inlet rod configuration. These four $0.48 \mathrm{~cm}$ (0.19 in.) diameter rods protruded about 25 percent into the flow passage and were intended to generate specific rod-rotor interaction modes. These rods were positioned $6.79 \mathrm{~cm}$ (2.67 in.) from the rotor stacking line plane. According to Eq. (1), circumferential mode orders, $m$, of $0, \pm 4, \pm 8, \pm 12$, etc. may be expected from this interaction. Figure 6 is a representative spectrum of the mode sound 
pressure levels as a function of circumferential mode number. These data are for 102 percent design rotor speed. The microphone measuring point was $5.00 \mathrm{~cm}$ (1.97 in.) axially immersed from the inlet highlight, and radially $1.10 \mathrm{~cm}$ (0.43 in.) from the inlet flow surface. The BPF tone for the 40-vane stator configuration is predicted to be cut-off. However, there is still evidence of considerable modal activity for the clean inlet configuration. (At $2 \mathrm{BPF}$ the $\mathrm{m}=-8$ circumferential mode is expected to be cut-on.) The sideline SPL directivity of Fig. 4 likewise showed some residual $\mathrm{BPF}$ tone for the 40 -vane stator. Introduction of the four inlet rods shows the expected increase for the rod-rotor interaction tone levels.

Figure 7 shows BPF tone sideline directivities for the clean inlet and four-rod configurations at 102 percent design speed. The SPL for the inlet rod configuration is typically $10 \mathrm{~dB}$ or more greater than that for the clean inlet. Also, note that the maximum tone level for the inlet rod configuration occurs in the forward quadrant rather than in the rear quadrant as was the case for the 22-vane rotor-stator interaction tone of Fig. 4. This is consistent with the concept that rod-rotor interaction noise is generated at the rotor face and is not attenuated by traversing the rotor flow field before leaving the fan inlet. The modal theory of Ref. 8 was used to predict mode maximum level angular locations, and these are noted for the four-rod directivity in Fig. 7. The predicted peak sideline angles are in reasonable agreement with the data. However, some significant peaks, such as that at $\Theta=118^{\circ}$ for the four-rod configuration are not predicted by theory. As previously discussed, this may be due to somewhat incorrect selection of input parameter values for Eqs. (2) and (3).

The fundamental rotor-stator interaction tone for the 22-vane stator is cut-on. Figure 8 shows the sideline BPF tone directivity for the 22-vane stator ADP configuration. Except for vane number, the cut-on ADP configuration of Fig. 8 is the same as the cut-off, clean inlet configuration of Fig. 7. Peak locations for predicted acoustic modes are indicated, and are in good agreement with observed peaks in the data. However, there are significant additional data peaks which are not predicted by theory.

\section{Effect of Blade Setting Angle}

The ADP is designed to "takeoff" with a rotor blade setting angle of $-11^{\circ}$ from the reference cruise setting angle. The model was tested over a range of blade setting angles from $-7^{\circ}$ to $-18^{\circ}$, with $-7^{\circ}$ being the most highly-loaded case with a correspondingly highest mass flow.

Figure 9 shows the change in BPF SPL as a function of blade setting angle for the 40- and 22-vane stator configuration. At 86 percent design speed the cut-off 40 -vane stator data shows little sensitivity to blade loading (Fig. 9(a)), while the cut-on 22-vane stator shows about a $5 \mathrm{~dB}$ tone level increase from $-14^{\circ}$ to $-7^{\circ}$ blade setting angle. This tone level is significantly greater than would be predicted by changes in thrust level $(\Delta \mathrm{dB}$ $=10 \log$ (thrust ratio)). Thrust changes alone account for only $1.5 \mathrm{~dB}$ when the blade setting angle is changed from $-7^{\circ}$ to $-18^{\circ}$. Although not predicted to be cut-on, the 40-vane stator data begins to show trends similar to (but significantly lower in level) those of the 22-vane stator data at 107 percent speed (Fig. 9(b)).

$\underline{\text { Effect of inlet length }}$

Three inlet lengths were tested with the ADP model. Aerodynamic performance was essentially identical for these three inlets. Figure 10 shows sideline BPF tone directivities for the three inlet lengths with the model operating at 107 percent design speed. These data are for the 40-vane stator, short spinner and nozzle, and $-11^{\circ}$ blade setting angle. The directivity for the long inlet is up to $10 \mathrm{~dB}$ lower than the directivities for the other two inlets in the forward quadrant. The occurrence of the highest levels in the forward 
quadrant are typical for rotor-inflow interaction, suggesting that at this highest test speed there may be some unidentified inflow irregularities which are interacting with the rotor. Inspection of the overlay of the three inlet contours in Fig. 2 shows that only the long inlet extends upstream beyond the short spinner highlight, as opposed to the other two inlets which form an annulus with the spinner. Therefore the mode release plane (assumed to be the inlet highlight plane) is different for the long inlet, and therefore may have a somewhat different acoustic attenuation characteristic.

Figure 11 extends the results of the previous figure to show the maximum upstream BPF tone level for each inlet as a function of rotor speed. Again, there is about a $5 \mathrm{~dB}$ difference between levels for the long inlet and those for the other two inlets. The BPF tone levels for all inlets - and especially for the short inlet-take a sharp upward turn as the fan speed is increased to 107 percent design.

$\mathrm{BPF}$ tone level differences between inlet configurations were not as significant for the 22-vane cut-on data. Figure 12 shows the maximum upstream BPF tone level as a function of rotor speed, while Fig. 13 shows similar results covering the entire sideline directivity. There is evidence that acoustic attenuation of rotor-stator interaction noise attempting to propagate upstream through the rotor flow becomes more significant at the higher rotor speeds (Fig. 12). The cut-on results of Fig. 13 show an expected increase in tone level with rotor speed as would be expected for rotor-stator interaction tones (in contrast with the relatively small tone level changes with speed shown for the cut-off results of Fig. 11).

\section{Effect of Ducted Propeller Axis}

\section{Angle-of-Attack}

Tone level variations in the circumferential acoustic field of a free propeller operating at rotational axis angle-of-attack has been well-documented in the literature. ${ }^{9}$ Cyclical blade loading resulting from non-axial inflow produces a corresponding asymmetrical circumferential noise field. In concept, a ducted propeller should exhibit an increasing acoustic response to non-zero angle-of-attack as the outer shroud length decreases. At 86 percent design speed (Fig. 14) the ADP appears to exhibit this acoustic response, showing the greatest BPF tone level sensitivity to propeller axis angle-of-attack for the short inlet, and progressively less acoustic response associated with longer inlet length.

However, at rotor speeds above 86 percent design the ADP shows little acoustic sensitivity to angle-of-attack regardless of test inlet length. For example, at 96 percent design speed the BPF tone level is essentially the same for all inlets and all test angles-of-attack at corresponding sideline angles. This result shows that the rotor inflow is conditioned by even a short inlet length to negate angle-ofattack effects on inflow-rotor acoustic interaction. The results in Fig. 14 are normalized at $0^{\circ}$ angle-of-attack.

Figure 15 shows corresponding results at 102 percent speed. Peak BPF tone levels for ta single-rotation advanced turboprop (SR-7A, Ref. 9) are superimposed on this figure, showing the unducted propeller's sensitivity to angle-of-attack effects.

The translating microphone probe was fixed to the tunnel floor and aligned with the tunnel flow. Consequently, acoustic modes which propagate at a particular angle relative to the ADP axis-of-rotation will appear at different locations along the sideline directivities as the model angle-of-attack is changed, moving forward with increasing propeller axis angle-of-attack. Figure 16 shows sideline directivities for the model at angles-of-attack from $0^{\circ}$ to $30^{\circ}$. Data are for the cut-on 22-vane stator with the rotor operating at 96 percent speed. The modal theory of Ref. 8 was used to designate the sideline angular location of a representative forward-radiating mode $(-12,5)$, designated mode " $F$," and two overlapping aft-radiating modes $(-6,2)$ and 
$(-12,3)$ designated mode "A." With geometric correction, peaks in the sideline directivities corresponding to modes " $\mathrm{F}$ " and " $\mathrm{A}$ " are evident in the sideline directivities at all test propeller axis angles-of-attack.

\section{Effect of Spinner and Nozzle Length}

In general, no appreciable acoustic change was associated with spinner length for the cutoff stator. (The cut-on 22-vane stator was only tested with the short spinner.) The one minor exception to this observation was for the 40 -vane stator at 96 percent rotor speed. At this test condition there is some change in the directivity shape and level for the longer, plug spinner (Fig. 17). The reason for this difference is unknown, although a plausible explanation may be that BPF tone noise is reflected from the longer spinner and in some manner generates a measurable interference with the directly radiating tone noise at this particular rotor speed and tone frequency.

Three nozzle configurations (see Table I) were tested with the 40 -vane stator. Aside from aerodynamic loading changes, no measurable acoustic changes were associated with nozzle type, although changes in fan loading caused by nozzle restriction have been associated with changes in broadband noise levels as noted in the literature.

\section{Effect of Rotor Rub Strip}

The ADP model was tested with both smooth and grooved rotor rub strips. No fundamental BPF tone level changes were associated with type of rub strip; however, changes in rub strip configuration may yield aerodynamic benefits.

\section{Summary of Results}

Aero-acoustic tests on a model Advanced Ducted Propeller (ADP) were performed in the NASA Lewis 9 - by 15 -Foot Low Speed Anechoic Wind Tunnel at a simulated takeoff flight speed of Mach 0.2. The ADP model was designed and manufactured by the
Pratt \& Whitney Division of United Technologies. The model was tested with three inlet lengths, three nozzle sizes, two spinner types, and two types of rotor rub strip. The model had a 16-blade rotor. Tests were made with two stator vane numbers ( 22 and 40 ) to achieve cut-on and cut-off conditions with respect to the fundamental rotor-stator interaction tone. The model was tested over a range of rotor blade setting angles and propeller axis angles-of-attack. Acoustic data were acquired with a translating microphone probe which was attached to the tunnel floor. A unique rotating microphone probe was used to identify and measure rotating acoustic interaction modes propagating in the fan inlet. The model with the rotating probe was tested with both a clean inlet and with four rods in the inlet to generate known interaction modes.

The following significant results were observed in this study:

1. The fundamental rotor-stator interaction tone for the cut-on 22-vane stator was up to $20 \mathrm{~dB}$ higher than that for the cut-off 40-vane stator, with the maximum tone level occurring in the aft quadrant. This observed higher tone level in the aft quadrant may relate to tone attenuation associated with propagation upstream through the rotor flow field as suggested in an earlier, referenced study.

2. There was still some residual fundamental tone content observed for the cut-off 40 -vane stator. This residual tone was somewhat higher in the forward quadrant, suggesting that it may arise from some unidentified inflow-rotor interaction.

3. Data from the rotating inlet acoustic probe effectively identified acoustic mode circumferential order and magnitude, including residual tones for the cut-off stator.

4. The BPF tone level for the long inlet and 40-vane stator was consistently about $5 \mathrm{~dB}$ lower than corresponding tones for the medium and short inlets at all rotor test 
speeds. This may relate to the highlight of the long inlet being upstream of the spinner highlight, while the highlights for the other two inlets were in a region which formed an exit annulus with the spinner.

5. The BPF tone level was essentially unaffected by propeller axis angle-of-attack for rotor speeds of 96 percent design and higher, indicating that all inlet lengths effectively conditioned the rotor inflow. However, the maximum sideline tone level "below the model" did increase with angle-of-attack at 86 percent design rotor speed, with the short inlet being most sensitive to angle-of-attack.

\section{$\underline{\text { References }}$}

1. Hager, R.D. and Vrabel, D., "Advanced Turboprop Project," NASA SP-495, 1988.

2. Groeneweg, J.F. and Bober, L.J., "NASA Advanced Propeller Research," NASA TM-101361, 1988.

3. Tyler, J.M. and Sofrin, T.G., "Axial Flow Compressor Noise Studies, SAE Transactions," Vol. 70, 1962, pp. 309-332.

4. Dahl, M.D. and Woodward, R.P., "Comparison Between Design and Installed
Acoustic Characteristics of NASA 9- by 15-Foot Low-Speed Wind Tunnel Acoustic Treatment," NASA TP-2996, 1990.

5. Philpot, M.G., "The Role of Rotor Blade Blockage in the Propagation of Fan Noise Interaction Tones," AIAA Paper 75-447, Mar. 1975.

6. Topol, D.A., Holhubner, S.C., and Mathews, D.C., "A Reflection Mechanism for Aft Fan Tone Noise from Turbofan Engines," AIAA Paper 87-2699, Oct. 1987.

7. Sofrin, T.G. and Mathews, D.C., "Asymmetric Stator Interaction Noise," AIAA Paper 79-0638, Mar. 1979.

8. Rice, E.J., Heidmann, M.F., and Sofrin, T.G., "Modal Propagation Angles in a Cylindrical Duct with Flow and Their Relation to Sound Radiation," AIAA Paper 79-0183, Jan. 1979. (Also, NASA TM-79030.)

9. Woodward, R.P., "Measured Noise of a Scale Model High Speed Propeller at Simulated Takeoff/Approach Conditions," AIAA Paper 87-0526, Jan. 1987. (Also, NASA TM-88920.) 
TABLE I.-ADP DESIGN PARAMETERS

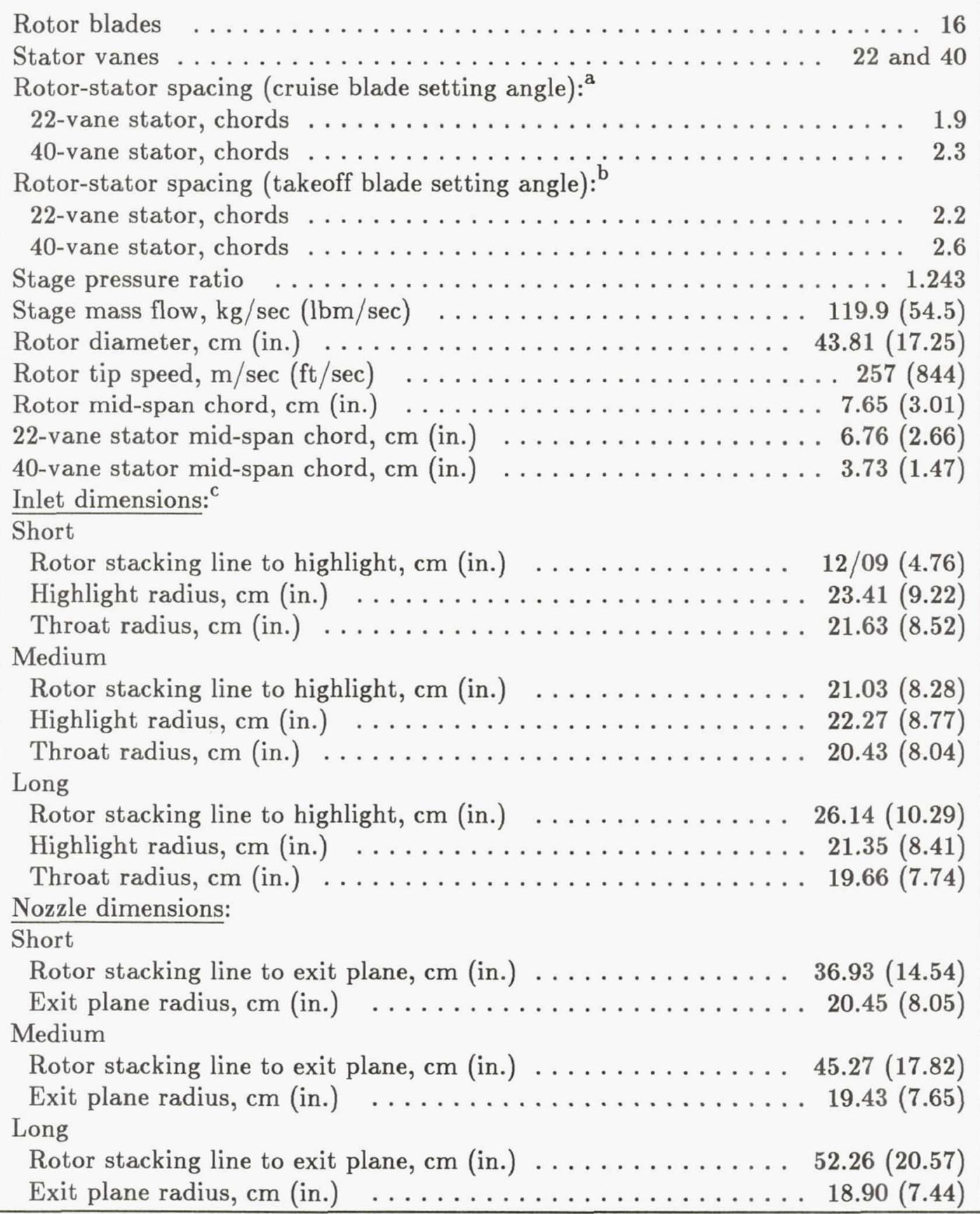

${ }^{\text {a }}$ Rotor mid-span chord. Listed chord values are for aerodynamic chord.

${ }^{\mathrm{b}}$ Cruise blade setting angle $-11^{\circ}$.

${ }^{\mathrm{c}} \mathrm{F}$ an face to rotor stacking line at cruise blade setting angle is $3.07 \mathrm{~cm}$ (1.21 in.). 
TABLE II.-ADP ACOUSTIC TEST MATRIX

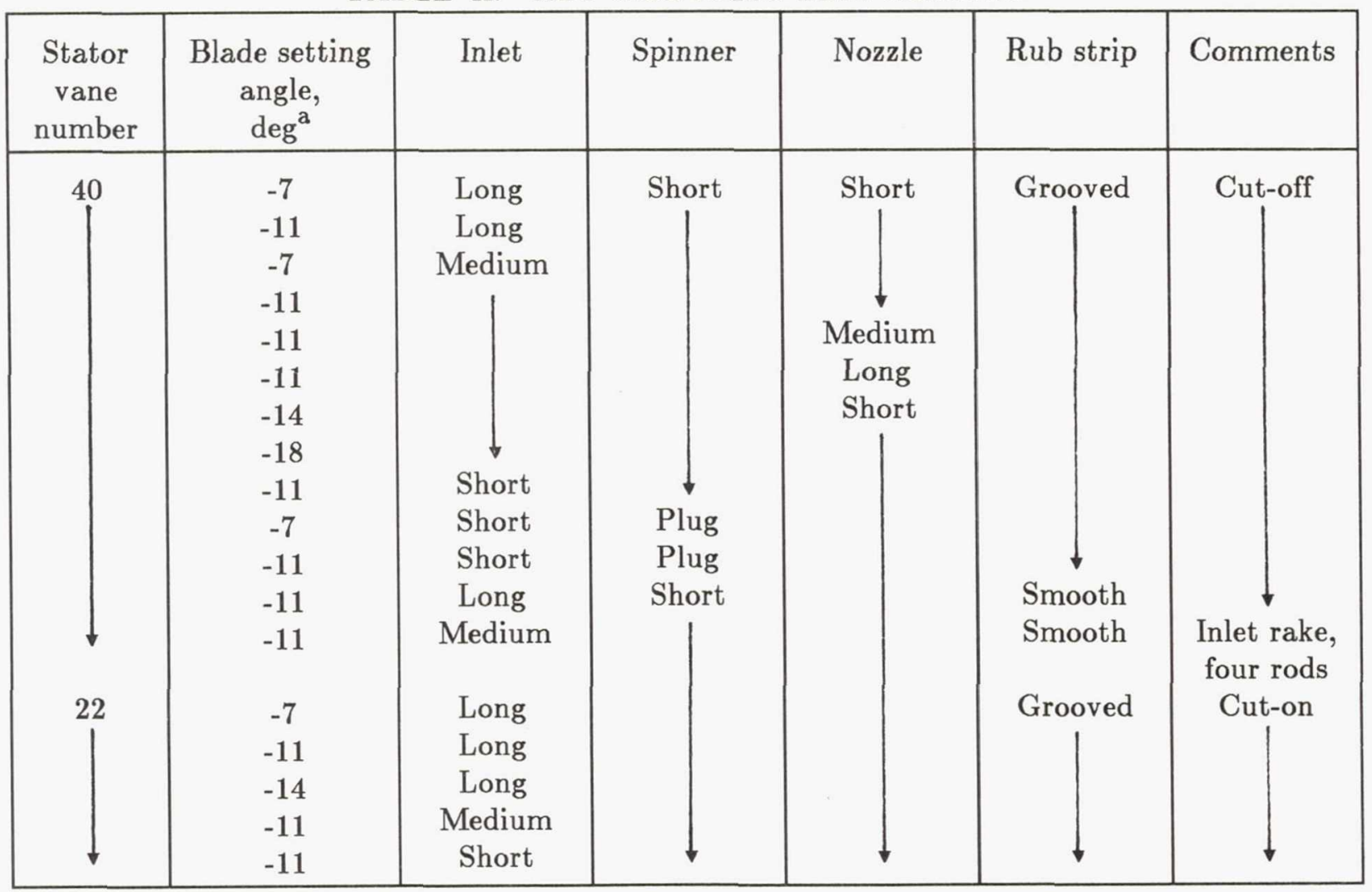

${ }^{\mathrm{a}}$ Measured from design cruise blade setting angle. 


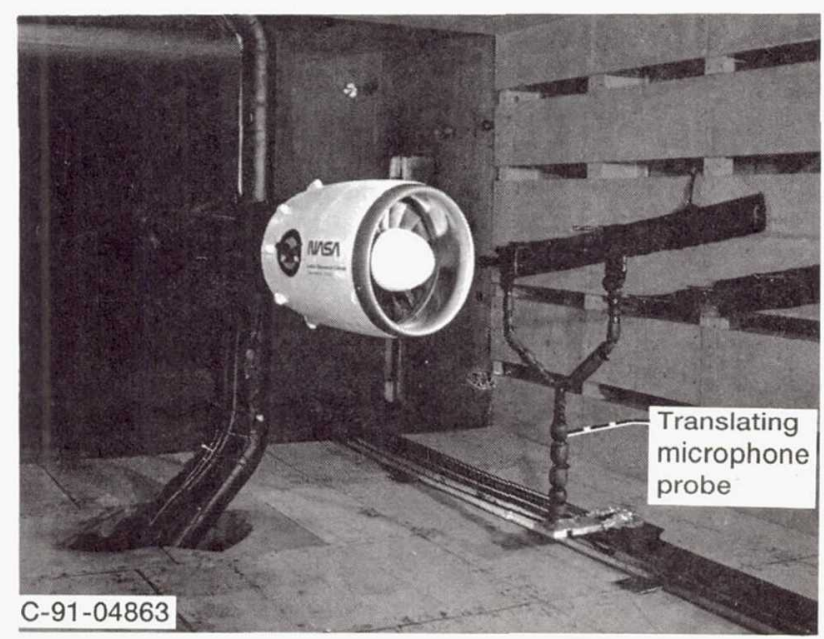

(a) Photograph of the advanced ducted propeller model installed in the $9 \times 15 \mathrm{ft}$ anechoic wind tunnel.

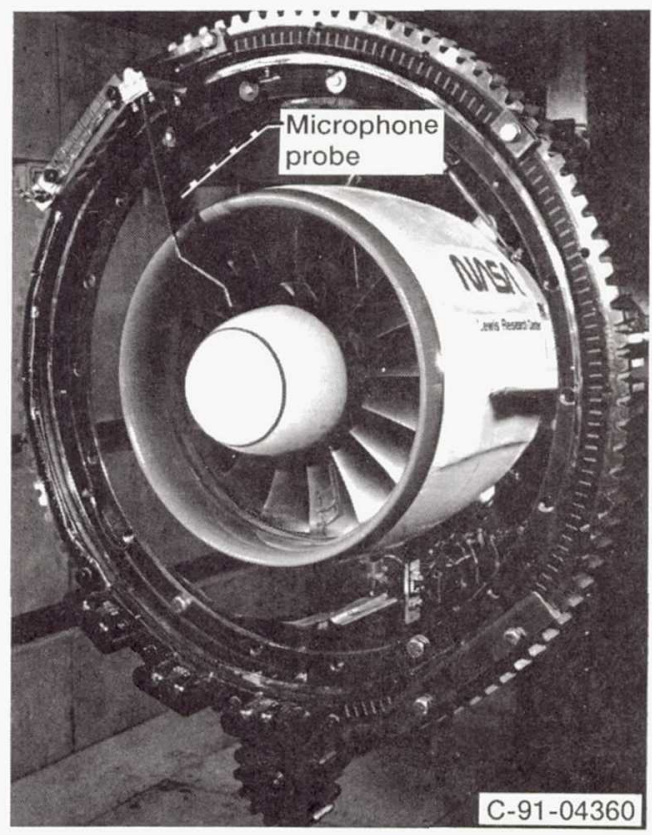

(b) Photograph of installed fan mode measurement probe.

Figure 1.-Advanced Ducted Propeller acoustic installation.

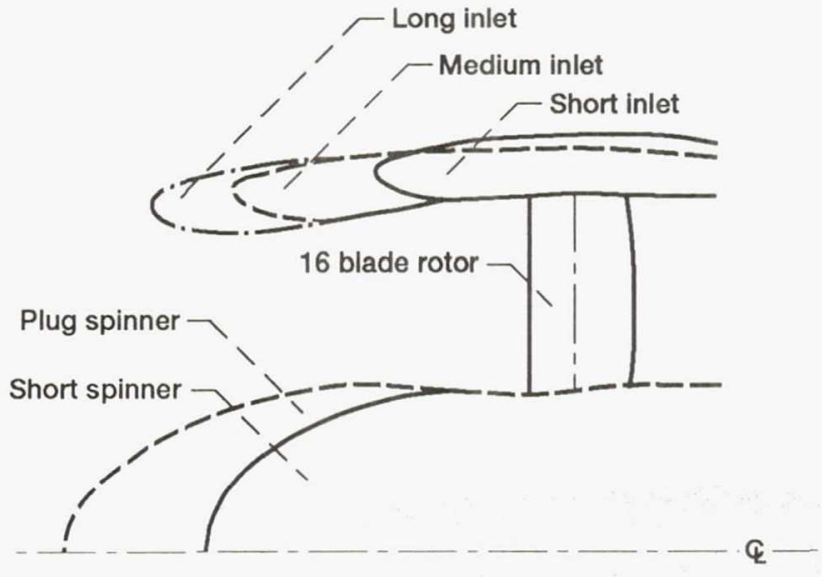

Figure 2.-ADP inlet configurations.

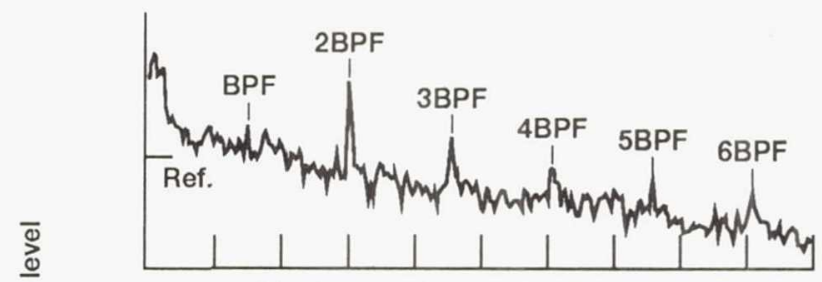

(a) 40-vane stator, cut-off.

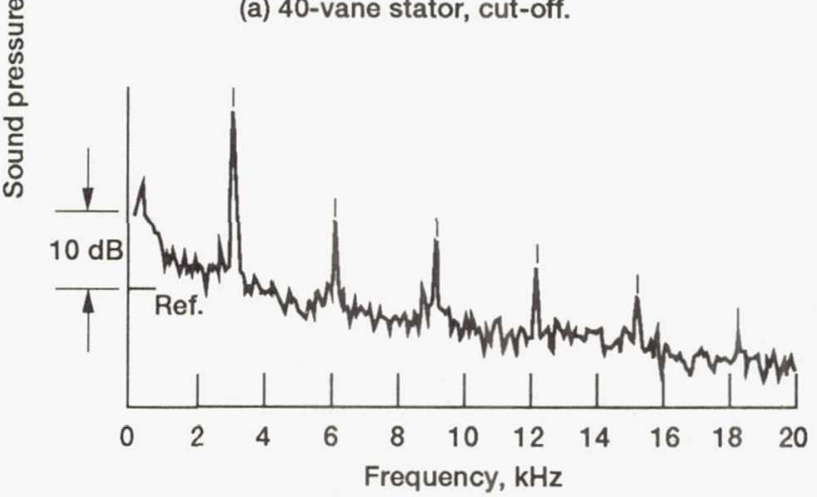

(b) 22-vane stator, cut-on.

Figure 3.-Typical sound pressure level spectra for cut-on and cut-off configurations $(102 \%$ design speed, long inlet, short spinner and nozzle, $\alpha=0^{\circ}, \beta=-11^{\circ}, \theta=83^{\circ}, M_{\infty}=0.2$ ). 


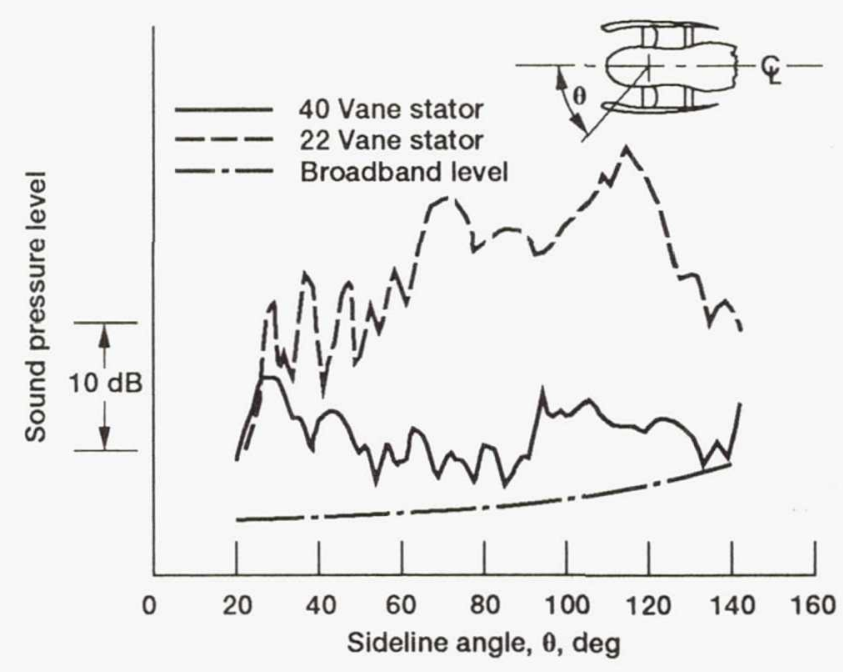

Figure 4.-Sideline BPF tone directivities for 40- and 22-vane stators $(102 \%$ design speed, long inlet, short spinner and nozzle, $\alpha=0^{\circ}, \beta=-11^{\circ}, M_{\infty}=0.2$ ).

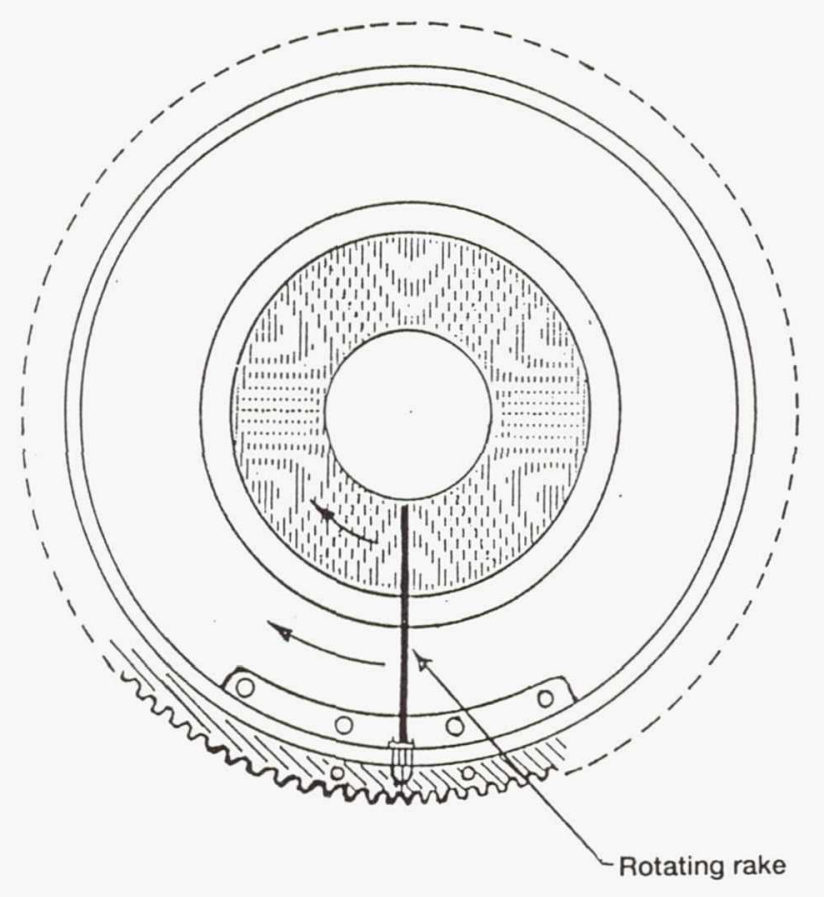

Modal pattern

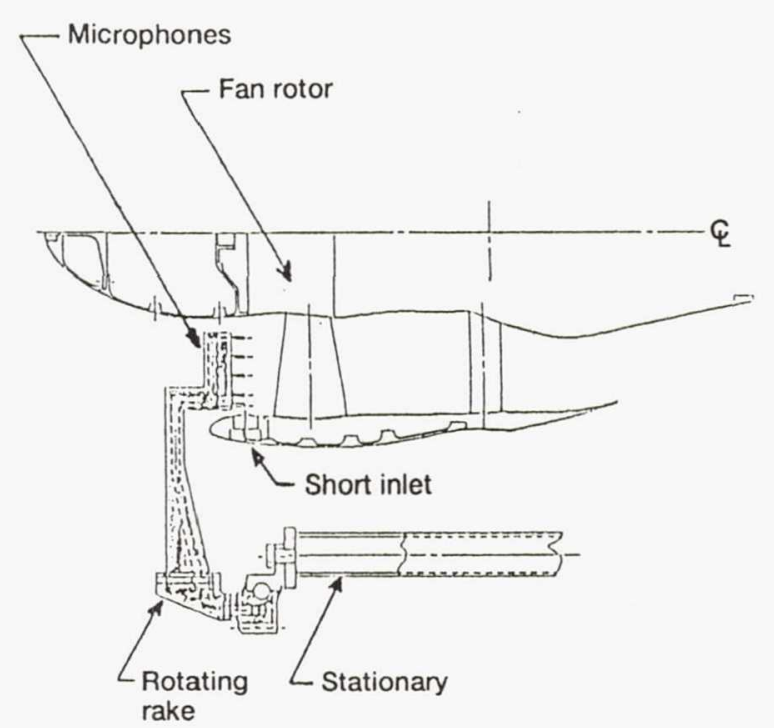

Figure 5.-Details of fan mode measurement rake. 


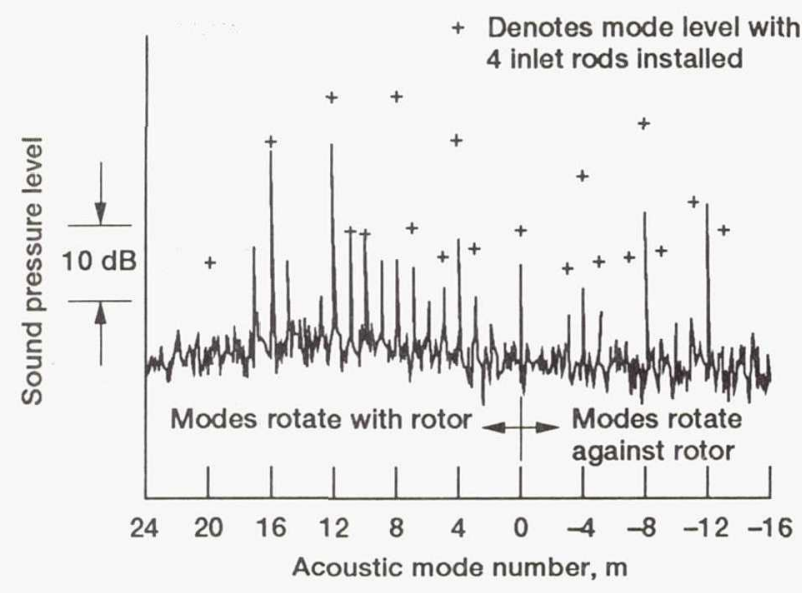

Figure 6.-Inlet acoustic mode levels (40-vane stator, $102 \%$ design speed, medium inlet, short spinner and nozzle, $\alpha=0^{\circ}, \beta=-11^{\circ}, M_{\infty}=0.2$ ).

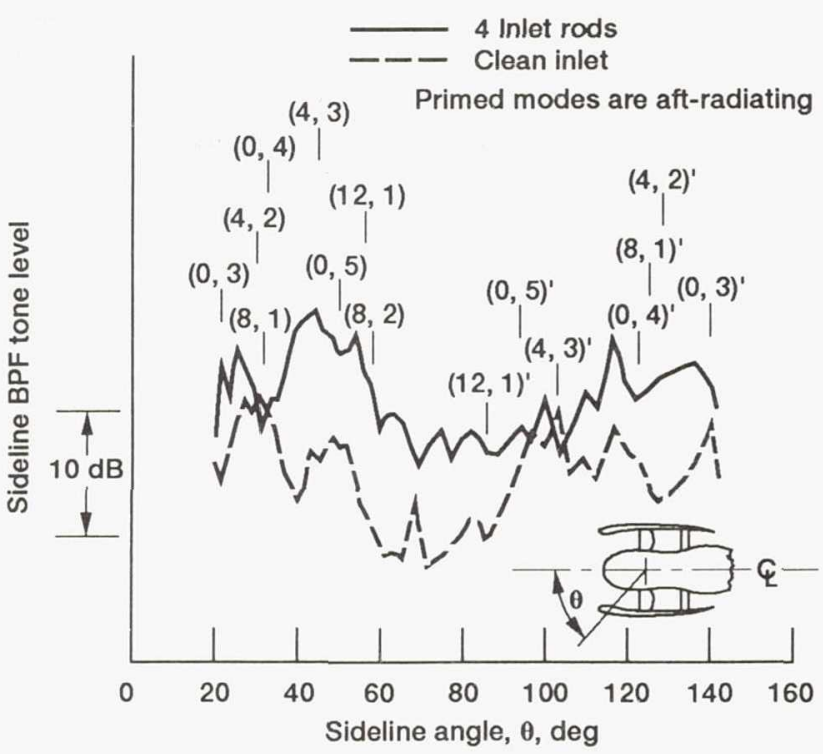

Figure 7.-Sideline directivities with and without inlet rods (40vane stator, $102 \%$ design speed, medium inlet, short spinner and nozzle, $\beta=-11^{\circ}, M_{\infty}=0.2$ ).

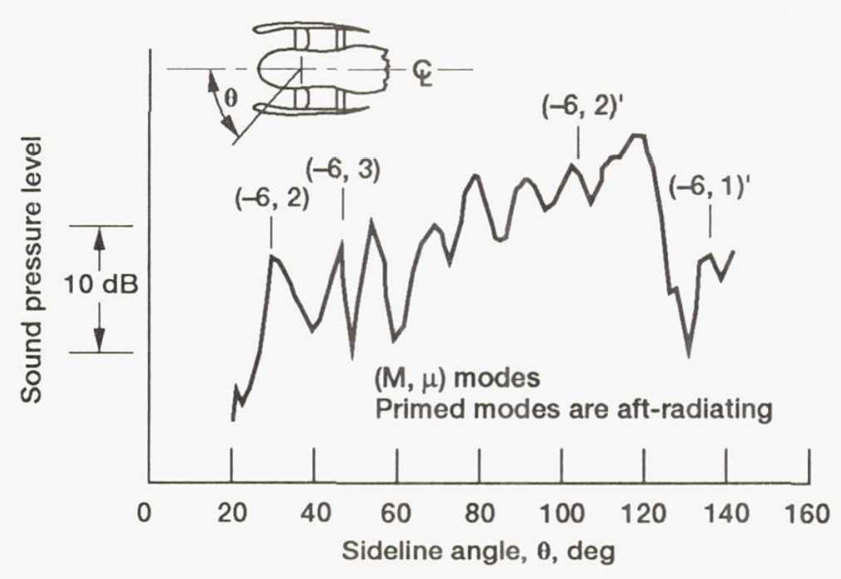

Figure 8.-ADP sideline directivity showing angular locations of principal lobe maximum level (BPF tone, 22-vane stator, $102 \%$ design speed, short inlet, spinner and nozzle, $\alpha=0^{\circ}$, $\beta=-11^{\circ}, M_{\infty}=0.2$ )

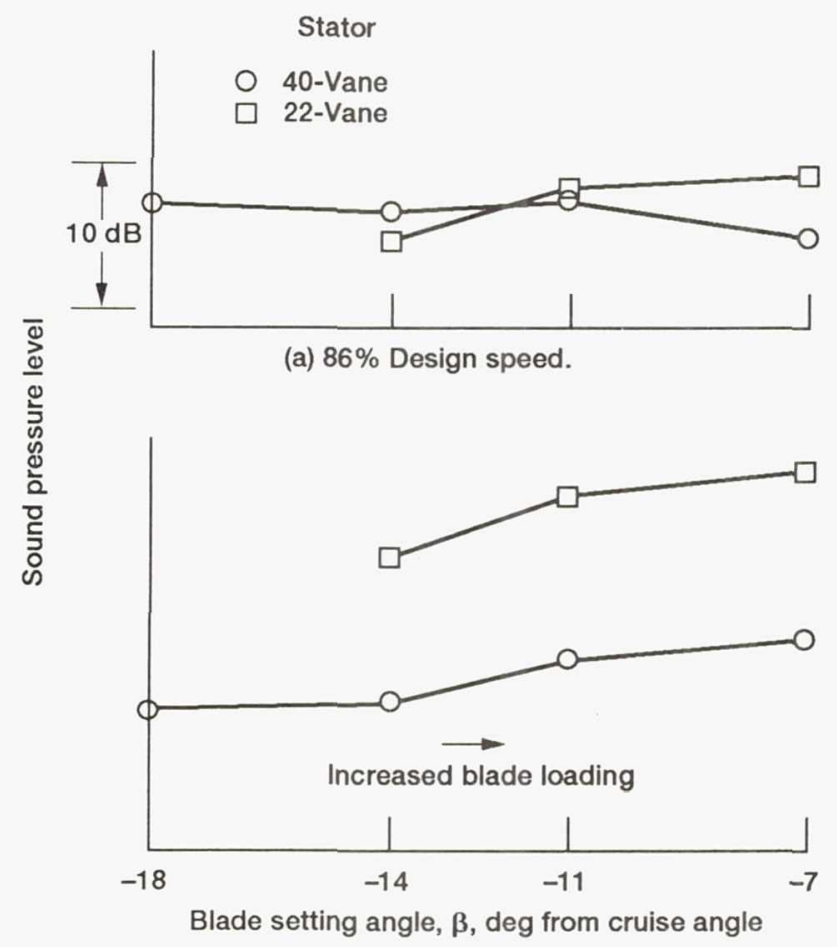

(b) $107 \%$ Design speed.

Figure 9.-Effect of blade loading on maximum sideline BPF tone level (22-vane stator with long inlet, 40-vane stator with medium inlet, short spinner and nozzle, $\alpha=0^{\circ}, M_{\infty}=0.2$ ). 


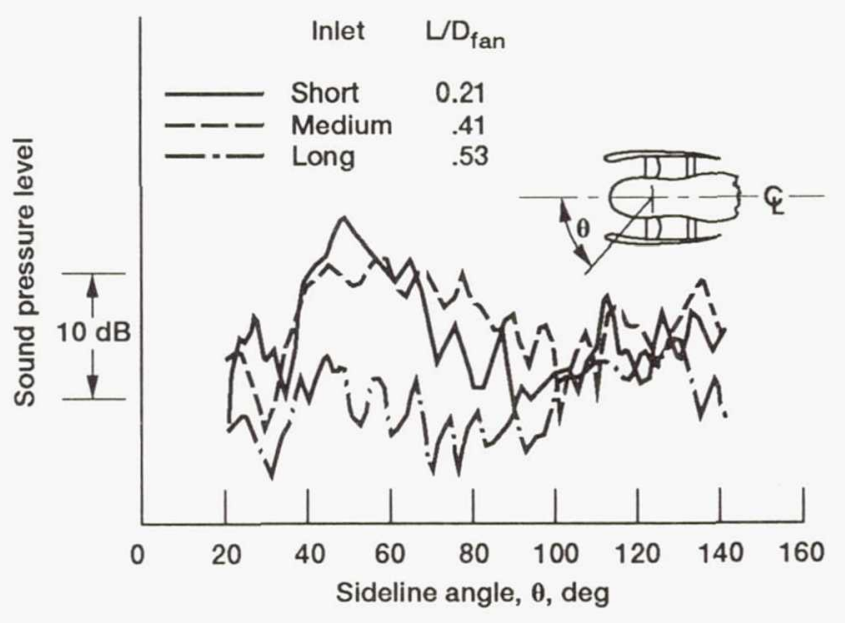

Figure 10.-Effect of inlet length on BPF tone directivity (40vane stator, $107 \%$ design speed, short spinner and nozzle, $\alpha=0^{\circ}, \beta=-11^{\circ}, M_{\infty}=0.2$ ).

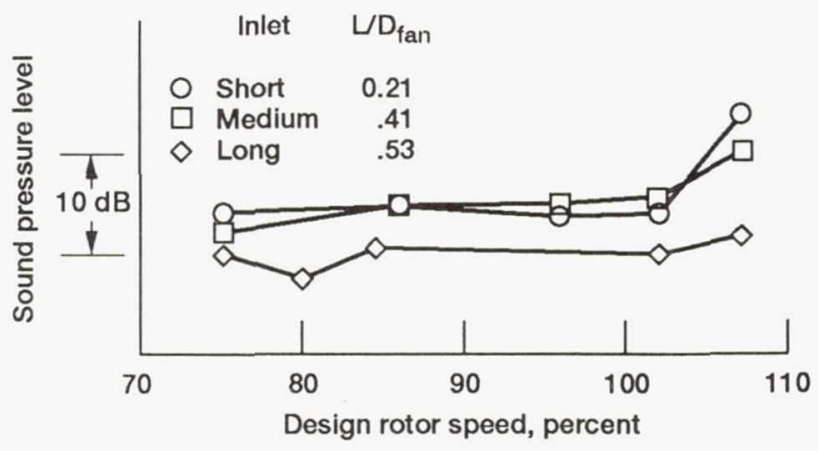

Figure 11.-Effect of inlet length on maximum upstream BPF tone level (40-vane stator, short spinner and nozzle, $\alpha=0^{\circ}$, $\beta=-11^{\circ}, M_{\infty}=0.2$ ).

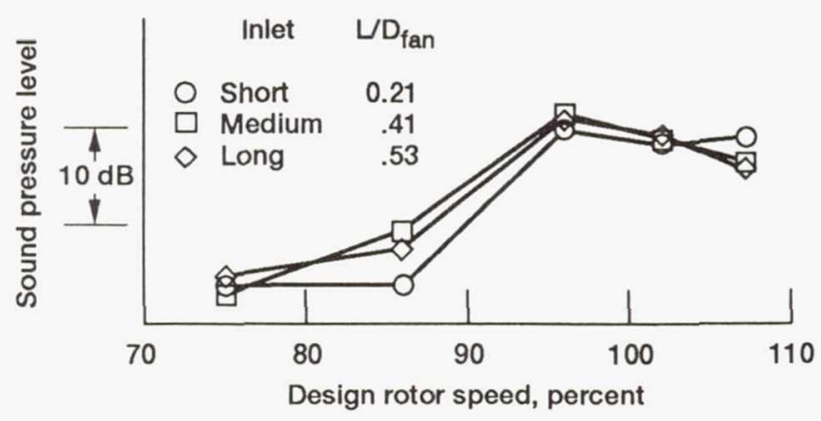

Figure 12.-Effect of inlet length on maximum upstream BPF tone level (22-vane stator, short spinner and nozzle, $\alpha=0^{\circ}$, $\beta=-11^{\circ}, M_{\infty}=0.2$ ).

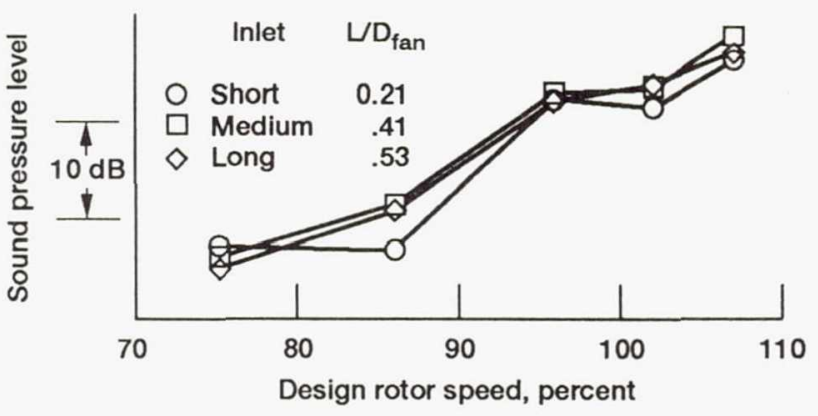

Figure 13.-Effect of inlet length on maximum sideline BPF tone level (22-vane stator, short spinner and nozzle, $\alpha=0^{\circ}$, $\beta=-11^{\circ}, M_{\infty}=0.2$ ).

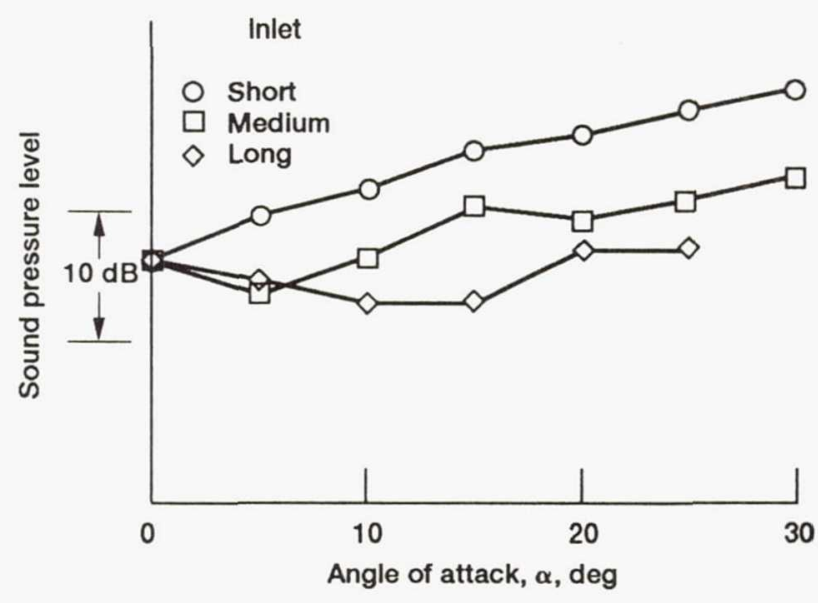

Figure 14.-Maximum sideline BPF tone level (22-vane stator, $86 \%$ design speed, short spinner and nozzle, $\beta=-11^{\circ}$, $M_{\infty}=0.2$ ).

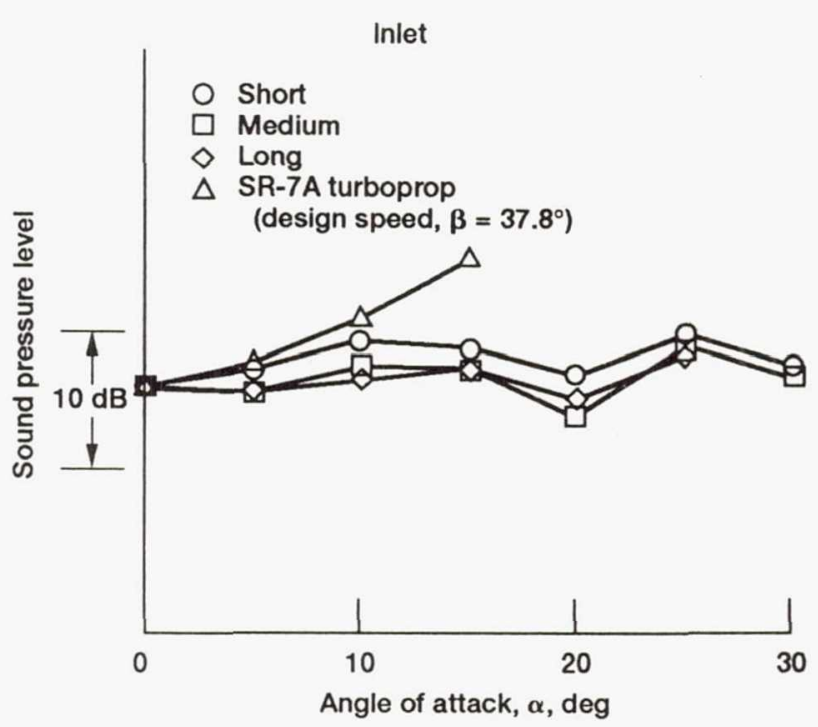

Figure 15.-Maximum sideline BPF tone level (22-vane stator, $102 \%$ design speed, short spinner and nozzle, $\beta=-11^{\circ}$, $M_{\infty}=0.2$ ). 


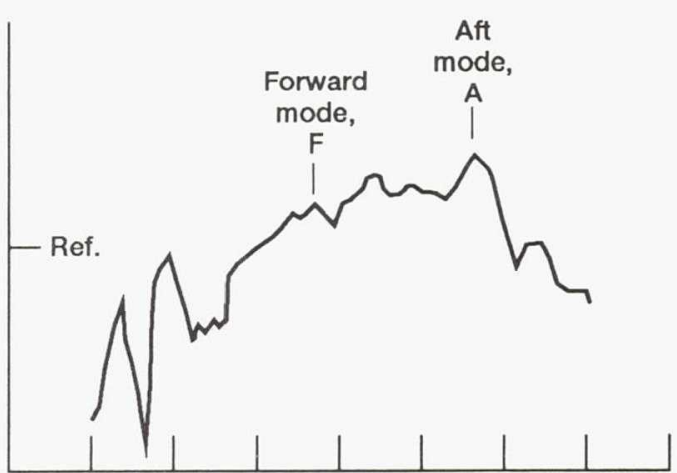

(a) $\alpha=0^{\circ}$.

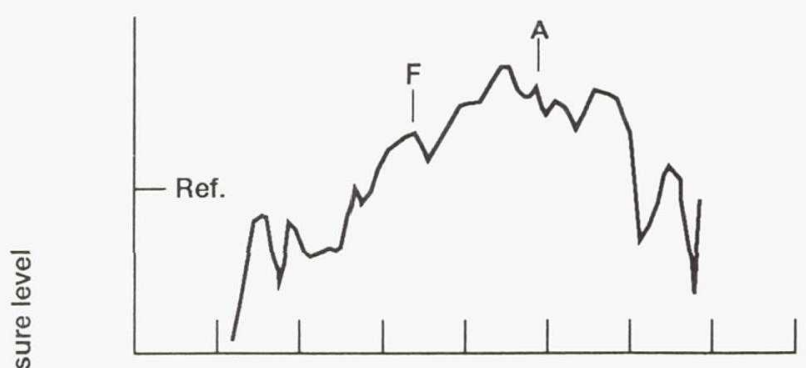

(b) $\alpha=10^{\circ}$.

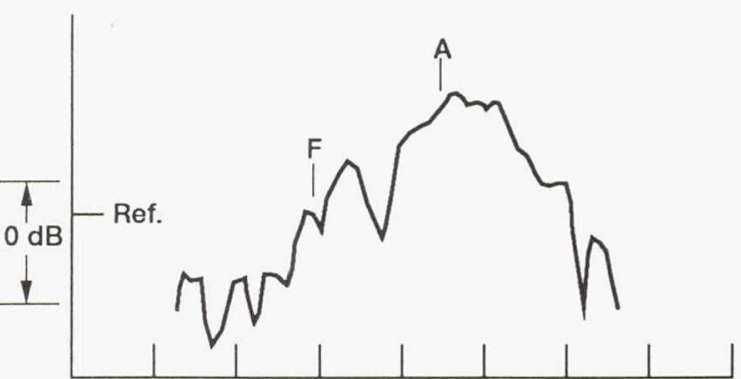

(c) $\alpha=20^{\circ}$.

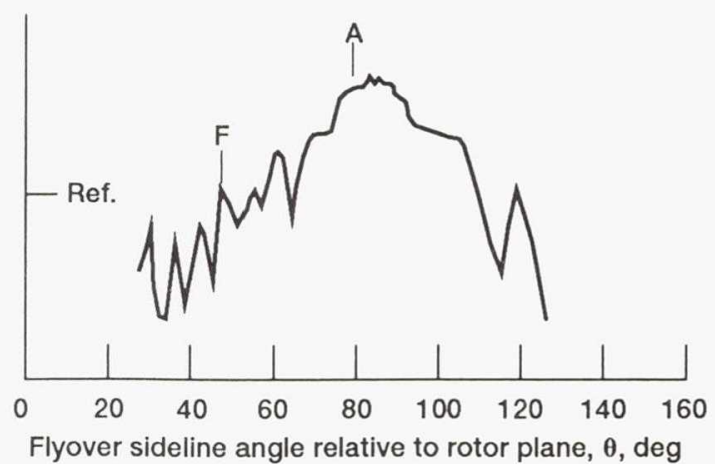

(d) $\alpha=30^{\circ}$.

Figure 16.-BPF tone sideline directivities at several propeller axis angles-of-attack. Representative inlet mode, "F", and aft mode, "A" are shown on each directivity (22-vane stator, $96 \%$ design speed, short inlet, short spinner and nozzle, $\beta=-11^{\circ}, M_{\infty}=0.2$ ).

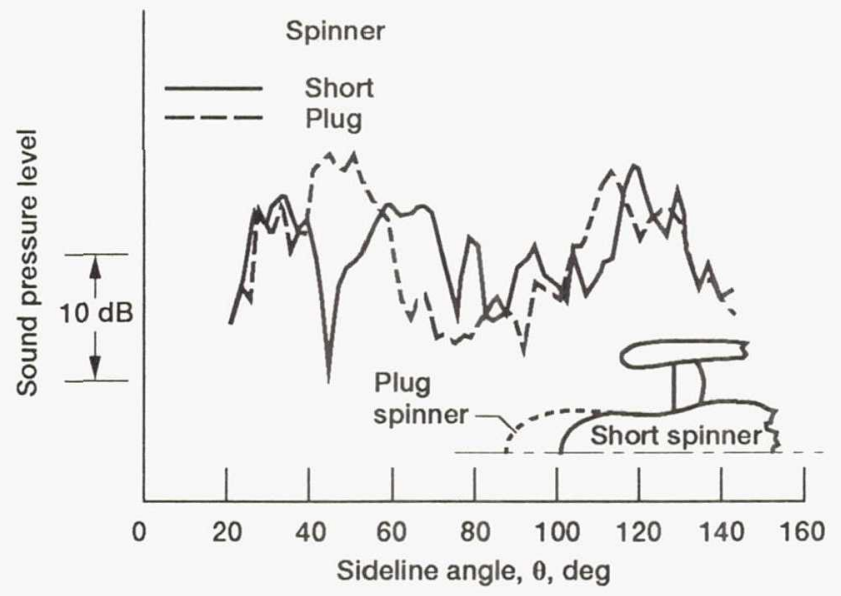

Figure 17.-Effect of plug spinner on sideline BPF tone directivity (40-vane stator, $96 \%$ design speed, short nozzle, $\alpha=0^{\circ}$, $\beta=-11^{\circ}, M_{\infty}=0.2$ ). 
Public reporting burden for this collection of information is estimated to average 1 hour per response, including the time for reviewing instructions, searching existing data sources, gathering and maintaining the data needed, and completing and reviewing the collection of information. Send comments regarding this burden estimate or any other aspect of this collection of information, including suggestions for reducing this burden, to Washington Headquarters Services, Directorate for information Operations and Reports, 1215 Jefferson Davis Highway, Suite 1204, Arlington, VA 22202-4302, and to the Office of Management and Budget, Paperwork Reduction Project (0704-0188), Washington, DC 20503.

\begin{tabular}{|l|l|l|}
\hline 1. AGENCY USE ONLY (Leave blank) & 2. REPORT DATE & 3. REPORT TYPE AND DATES COVERED
\end{tabular}

\begin{tabular}{|c|c|c|}
1992 & Technical Memorandum \\
\hline
\end{tabular}

4. TITLE AND SUBTITLE

5. FUNDING NUMBERS

Far-Field Noise and Internal Modes From a Ducted Propeller

at Simulated Aircraft Takeoff Conditions

6. AUTHOR(S)

Richard P. Woodward, Lawrence A. Bock,

Laurence J. Heidelberg, and David G. Hall

7. PERFORMING ORGANIZATION NAME(S) AND ADDRESS(ES)

National Aeronautics and Space Administration

Lewis Research Center

Cleveland, Ohio 44135-3191

WU $-535-03-10$

9. SPONSORING/MONITORING AGENCY NAMES(S) AND ADDRESS(ES)

National Aeronautics and Space Administration

Washington, D.C. 20546-0001

8. PERFORMING ORGANIZATION REPORT NUMBER

E -6747

11. SUPPLEMENTARY NOTES

Prepared for the 30th Aerospace Sciences Meeting and Exhibit sponsored by the American Institute of Aeronautics and Astronautics, Reno, Nevada, January 6-9, 1992. Richard P. Woodward and Laurence J. Heidelberg, NASA Lewis Research Center; Lawrence A. Bock, Pratt \& Whitney, East Hartford, Connecticut; David G. Hall, Sverdrup Technology, Inc., Lewis Research Center Group, 2001 Aerospace Parkway, Brook Park, Ohio 44142. Responsible person, Richard P. Woodward, (216) 433-3923.

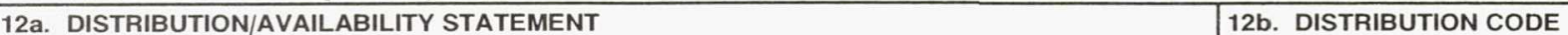

Unclassified - Unlimited

Subject Categories 71 and 07

\section{ABSTRACT (Maximum 200 words)}

The ducted propeller offers structural and acoustic benefits typical of conventional turbofan engines while retaining much of the aeroacoustic benefits of the unducted propeller. A model Advanced Ducted Propeller (ADP) was tested in the NASA Lewis Low-Speed Anechoic Wind Tunnel at a simulated takeoff velocity of Mach 0.2. The ADP model was designed and manufactured by the Pratt \& Whitney Division of United Technologies. The 16-blade rotor ADP was tested with 22- and 40-vane stators to achieve cut-on and cut-off criterion with respect to propagation of the fundamental rotor-stator interaction tone. Additional test parameters included three inlet lengths, three nozzle sizes, two spinner configurations, and 2 rotor rub strip configurations. The model was tested over a range of rotor blade setting angles and propeller axis angles-of-attack. Acoustic data were taken with a sideline translating microphone probe and with a unique inlet microphone probe which identified inlet rotating acoustic modes. The beneficial acoustic effects of cut-off were clearly demonstrated. A $5 \mathrm{~dB}$ fundamental tone reduction was associated with the long inlet and 40-vane stator, which may relate to inlet duct geometry. The fundamental tone level was essentially unaffected by propeller axis angle-of-attack at rotor speeds of at least $96 \%$ design.

\begin{tabular}{|c|c|}
\hline $\begin{array}{c}\text { 14. SUBJECT TERMS } \\
\text { Shrouded propellers; Aircraft noise }\end{array}$ \\
\hline $\begin{array}{c}\text { 17. SECURITY CLASSIFICATION } \\
\text { OF REPORT } \\
\text { Unclassified }\end{array}$ & $\begin{array}{c}\text { 18. SECURITY CLASSIFICATION } \\
\text { OF THIS PAGE } \\
\text { Unclassified }\end{array}$ \\
\hline
\end{tabular}

\begin{tabular}{|c|c|}
\hline & $\begin{array}{l}\text { 15. NUMBER OF PAGES } \\
16\end{array}$ \\
\hline & $\begin{array}{r}\text { 16. PRICE CODE } \\
\mathrm{A} 03\end{array}$ \\
\hline $\begin{array}{l}\text { 19. SECURITY CLASSIFICATION } \\
\text { OF ABSTRACT } \\
\text { Unclassified }\end{array}$ & 20. LIMITATION OF ABSTRACT \\
\hline
\end{tabular}

